\title{
WestVirginiaUniversity
}

THE RESEARCH REPOSITORY @ WVU

Graduate Theses, Dissertations, and Problem Reports

2016

\section{Bee Natural History, Diversity, and Management in West Virginia}

Matthew McKinney

Follow this and additional works at: https://researchrepository.wvu.edu/etd

\section{Recommended Citation}

McKinney, Matthew, "Bee Natural History, Diversity, and Management in West Virginia" (2016). Graduate Theses, Dissertations, and Problem Reports. 6202.

https://researchrepository.wvu.edu/etd/6202

This Dissertation is protected by copyright and/or related rights. It has been brought to you by the The Research Repository @ WVU with permission from the rights-holder(s). You are free to use this Dissertation in any way that is permitted by the copyright and related rights legislation that applies to your use. For other uses you must obtain permission from the rights-holder(s) directly, unless additional rights are indicated by a Creative Commons license in the record and/ or on the work itself. This Dissertation has been accepted for inclusion in WVU Graduate Theses, Dissertations, and Problem Reports collection by an authorized administrator of The Research Repository @ WVU.

For more information, please contact researchrepository@mail.wvu.edu. 
The Role of Reculturalization in Adaptation: A Comparison of Humor Styles in the UK and U.S. Versions of The Office

\author{
Rachael A. McKinney
}

Thesis submitted

to the Reed College of Media

at West Virginia University

in partial fulfillment of the requirements for the degree of

Master of Science in

Journalism

Steve Ubranski, Ph.D., Chair

Bob Britten, Ph.D.

Jeffrey Moser, MFA

Tracy Morris, Ph.D.

Morgantown, West Virginia

2016

Keywords: Humor, Humor styles, Television sitcoms, Adaptation, Culture, Reculturalization, Personality, United States of America, Great Britain

Copyright 2016 Rachael McKinney 


\section{Abstract \\ The Role of Reculturalization in Adaptation: A Comparison of Humor Styles in the UK and U.S. Versions of The Office \\ Rachael McKinney}

Purpose - The purpose of this study was to conduct a content analysis of humor styles used in an original British television show and its adapted U.S. version.

Methodology - A total of 28 episodes from the UK and U.S. version of the television sitcom The Office were classified under the four humor styles described by Martin et al. (2003). Findings - Humor styles used in television sitcoms significantly differ between the two countries. The UK uses more aggressive and self-defeating humor than the U.S., while affiliative humor is the predominant humor style found in the U.S. and is used more frequently when compared to the UK.

Practical Implications - The findings reveal that cultural and personality differences should be taken into consideration when adapting television shows from one country to another. 


\section{Table of Contents}

\section{Page}

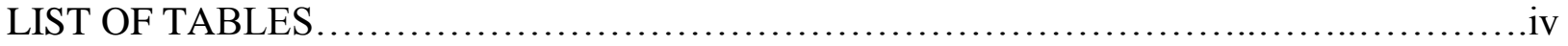

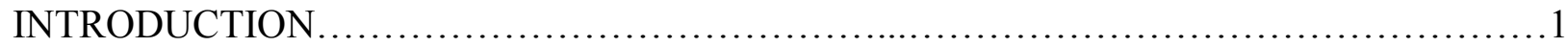

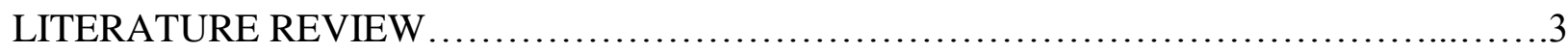

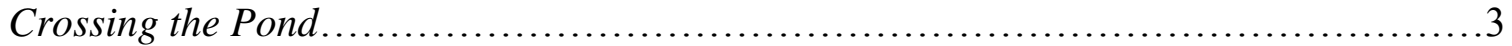

Humor Theory, Humor Styles, and Five-factor Theory ..............................5

The Big Five ....................................................................

RESEARCH HYPOTHESES .................................................... 17

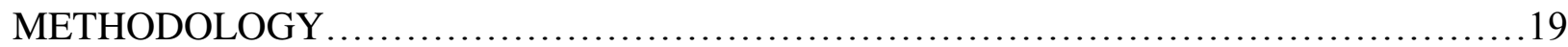

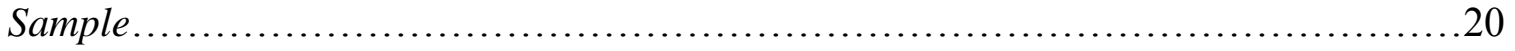

Coding Procedure...........................................................20

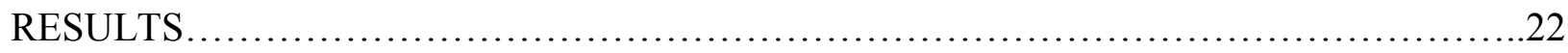

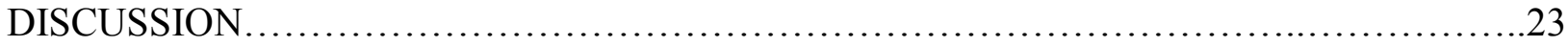

LIMITATIONS AND FUTURE RESEARCH......................................24

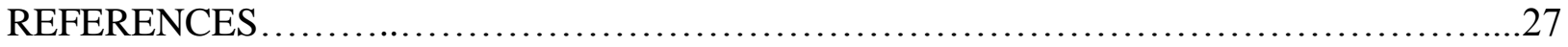

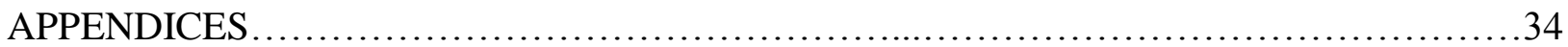




\section{List of Tables}

Table

Page

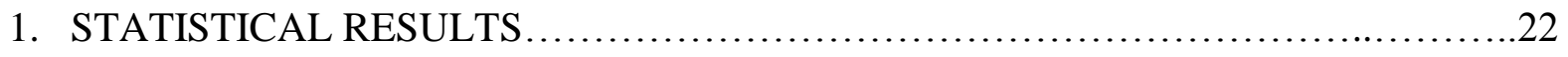




\section{Introduction}

Few things are as successfully and universally ingrained into daily life as humor. Although humor is a construct that has spread throughout every culture on earth (Howe, 2002, p. 252), there is some evidence that suggests differing preferences in the way humor is used and interpreted among cultures and nations. Some cultures may feel that there is a "time and a place" for it; other cultures may feel humor is entrenched into every aspect of life. The British are especially known for freely exercising the use of humor, no matter the topic at hand. Studies have found that perhaps the true defining characteristic of British humor was the value its people placed on it (Fox, 2008, p. 25). "Comedy plays an increasingly central role in British cultural life. ...comedy has emerged as a 'booming' multi-pound industry and an important staging point for understanding British cultural tastes and identities" (Friedman, 2011, p. 347). And while humor is thought to be an "underlying commonality" that makes us all human (Howe, 2002, p. 252), it only began to be recognized as a money-making industry in America in the early 1920s. In 1927, Bella Cohen wrote in The New York Times: "Humor today is manufactured, distributed, and sold..." (p. 6). Cohen (1927) tributes this to public entertainment ceasing to be a "haphazard Bohemianism" and instead becoming a "billion-dollar business" (p. 6).

In 2013, TIME reported that aside from NFL football, comedies brought in the highest ad rates, with advertisers willing to pay more than $\$ 325,000$ for 30 seconds of ad time (Newcomb, 2013). Humor was and continues to be the most important aspect of entertainment, with consumers wanting jokes more so than a storyline or romance. “...The plot is the least of anyone's worries. It is the laugh that counts" (Cohen, 1927, p. 6). 
Research conducted in the 1970s aimed to discover how prevalent humor was among a broad range of television programming genres; the results from this study showed that more than $80 \%$ of programs contain at least one attempt to be humorous (Alden, Mukherjee \& Hoyer, 1976, p. 508).

Since humor is so highly valued among consumers, businesses constantly seek ways to entertain and appease the public's desire for a good laugh (McGraw, 2011). Humor is a necessary component of human nature, that much like sex and eating, has been capitalized on in the media (Howe, 2002, p. 252). However, as widespread as it may be, "the content of humor may require adaptation when communicating in different cultural contexts" (Tatli \& Ozdemir, 2014, p. 973). For example, the use of humor in U.S. TV commercials has been found to contain more affiliative, aggressive, and selfdefeating humor than Mexican TV commercials, which use a greater degree of selfenhancing humor (Cruthirds, Wang, Wang, \& Wei, 2011).

Adaptations have long been viewed with disdain because they are often "hopelessly caught between conflicting aesthetic claims and rivalries" (Della Colletta, 2012, p. 1). However, various theoretical contributions including structuralist and poststructuralist analysis, narratology and semiology, reception and performativity theories, and cultural and postcolonial studies and media theory have resulted in a market that is able to adapt to different cultures and expand beyond borders, especially in a world of new media technologies (Della Colletta, 2012, p. 2). In order to be successful adaptations, a process of "reculturalization" must occur (Della Colletta, 2012, p. 4). As culture is an indication as to how media and art should be adapted, evidence shows that personality traits act as indicators on the cultural level (Allik, 2006, p. 122). 
This study aims to compare the humor styles in the UK and the U.S. versions of The Office on the basis of cultural and personality differences. Despite the popularity of humor in both countries, this research posits that culture and personality are determinant in the type of humor used in television shows.

\section{Literature Review}

\section{Crossing the Pond}

British humor was at first not readily accepted into mainstream American television. In the 1960s and early 1970s, action-adventure and historical dramas were the only British shows to capture the attention of American audiences; however, Monty Python's Flying Circus, which aired in the UK 1969-1974, changed that, claiming “...a fanatically devoted audience in the United States..." upon invading American television screens for the first time in 1974. (Miller, 2000, p. 111).

“Monty Python's Flying Circus represents a significant moment in the study of the crossover from British to American television..." (Landy, 2005, p. 25). The show was daring and untraditional, with nothing like it having been done before at the time of its creation (Miller, 2013). Although possessing a distinctly British humor, its success in the American market came as a result of its honest criticism of social and cultural processes (Miller, 2000, p. 111). The ability for Flying Circus to cross national boundaries was also due "to the character and evolution of the television medium" as well as its "atypical comic format" (Landy, 2005, p. 26). The U.S. was familiar with sketch comedy by this point, making American audiences more comfortable with the unique and different humor brought about by the importation of Flying Circus.

While the familiar format may have pleased U.S. audiences, Miller (2011) notes 
that the difference of British humor itself was what was appealing to America (p. 130). The main difference in the Flying Circus was its willingness to make a comedic source of institutional norms and conventions of television, such as game shows and beauty pageants. "American audiences who had grown up with and thus had a trained knowledge of the forms, if not necessarily the specific referents, being mocked could find the comic surprises in their treatment both appropriate and plausible" (Miller, 2011, p. 132).

Despite the success of Monty Python's Flying Circus, several humorous British adaptations have failed in America. One of the first failures came about shortly after Flying Circus, a show called Lotsa Luck that ran for only one season in 1973-174; its British counterpart $O n$ the Buses was a sensation that aired for seven seasons (Bell, n.d., para. 2). Some shows such as Men Behaving Badly and As If did not even air for a full season (Griffin, 2008). One show that was expected to be a successful adaptation from the UK market to the U.S. was The Coupling. This sitcom was widely popular in its native country and shared similarities with the popular American sitcom Friends, but the show's humor failed to translate to the American audience and was canceled before the first season had finished airing (Bell, n.d., para. 9).

When The Office first hit American airwaves in 2005, many viewers did not realize that the show had first aired in the UK in 2001 (Looney, 2012, p. 1). As the first successful British adaptation to the U.S. in decades, the creators of The Office in both countries somehow found a way to resonate with audiences in both cultures. Existing research has established several reasons as to why The Office was successfully adapted from the UK to the U.S. The "Americanization", or "reculturalization", of various elements of the series is among the most mentioned, giving substance to the idea that 
culture is essential to adaptation. "By adapting the original for local audiences, producers are able to make adjustments to better situate the show within the context of the local culture" (Griffin, 2008, p. 155).

Shows such as Monty Python's Flying Circus and The Office seem to be the exceptions and not the norm. The Office may contrast from Flying Circus' surreal humor by instead opting for a mundane, mockumentary that occurs in the workplace, but it does maintain one similarity: dichotomy. Even if culture influences whether certain jokes are successful when adapting a series, audiences still cling to elements of surprise and originality. One thing that has not changed, though, is the fact that humor is a reoccurring phenomenon in rhetoric. (Meyer, 2000, p. 310).

\section{Humor Theory, Humor Styles, and Five-factor Theory}

Communication is a key component in humor and humor theories because humor is a "message or interaction perceived by someone" (Meyer, 2000, p. 312), and humor can only occur when two separate entities are communicating with one another (Howe, 2002, p. 254). Television shows that are produced within a particular country often carry a distinct communication style that is representative of that country's national identity (Collins, 1990). Thus, humor styles in the context of television sitcoms is an important area that needs to be studied.

Humor is composed of several loosely related traits, including cognitive ability, aesthetic response, habitual behavior, emotion-related temperament trait, attitude, and/or coping strategies (Martin, Puhlik-Doris, Gray \& Weir, 2003, p. 49). Humor theorists have made attempts to identify an all-encompassing definition of the term but often only include the layers of joke telling or laughter (Looney, 2012, p. 14). Martin et al. (2003) 
define humor as "a stable personality trait or individual difference variable" (p. 49). This concept of humor lends to the idea that a link exists between personality and humor.

Several researchers have examined the relationship between personality and humor, but it is believed that the work of Martin et al. (2003) has been the most influential in this area to date (Rai \& Kumar, 2012, p. 335). In their work, four different styles of humor were distinguished: affiliative humor, self-enhancing humor, aggressive humor, and self-defeating humor (Martin et al., 2003, pp. 53-54). Each of these humor styles corresponds to a personality type(s).

This typology has been used in cross-cultural studies that found cross-cultural differences of humor usage existed (Kalliny, Cruthirds, \& Minor, 2006; Romero \& Cruthirds, 2006). The current research attempted to categorize the UK and U.S. versions of the sitcom The Office by these four humor styles developed by Martin et al. (2003).

\section{Affiliative humor.}

Individuals who engage in this type of humor tend to tell jokes and employ the use of spontaneous witty banter. This is often done in an attempt to put other people at ease and to create bonds. "This is an essentially non-hostile, tolerant use of humor that is affirming of self and others and presumably enhances interpersonal cohesiveness and attraction" (Martin et al., 2003, p. 53). This style of humor is related to the personality trait of extraversion.

For example, affiliative humor is frequently seen in the U.S. version of The Office between characters Jim and Pam. In the season one episode "Basketball" (Daniels, 2005), the office staff goes head to head with the warehouse workers in a game of basketball, where there is a wager that the losing team would work the upcoming weekend. Jim is 
confident in his ability to impress Pam with his skills, and prior to the game asks if she is going to wish him luck. Pam responds in joking manner by saying "Yeah, you're gonna need it." The two laugh, and Jim asks if Pam is "trash-talking" him. Pam then tells Jim that her fiancé, who is playing for the opposing team, is competitive and already had plans for the weekend. Jim teases back that he too has weekend plans, and that Pam would be welcome to join him since Roy would be working after losing the game. This scene plays out in a non-hostile, banter-like manner, which the literature (Martin et al, 2003) supports as being consistent with the affiliative humor style.

\section{Self-enhancing humor.}

This style of humor is closely related to coping humor, and "involves a generally humorous outlook on life, a tendency to be frequently amused by the incongruities of life, and to maintain a humorous perspective even in the face of stress or adversity" (Martin et al., 2003, p. 53). This type of humor is negatively associated with neuroticism but is likely to be connected to openness, extraversion, agreeableness, and conscientiousness.

In the U.S. version's season two episode "The Fire" (Daniels, 2005), the entire office is forced to evacuate due to a fire. While waiting to reenter the building, boss Michael Scott takes an interest in the new employee Ryan. Dwight grows increasingly jealous, and when Michael mentions that he had left his cell phone in the office, Dwight immediately takes it upon himself to rush back inside to fetch it. When Dwight emerges from the building, he announces that he has discovered that the fire had been started by Ryan, who had left a cheese pita on the oven. Dwight and Michael proceed to mock Ryan and dub him "The Fire Guy.” Ryan responds by simply laughing at his mistake, saying "I can't believe I started the fire." As described by Martin et al. (2003), this behavior of 
being able to laugh at one's self is representative of self-enhancing humor.

\section{Aggressive humor.}

Teasing, ridicule, and sarcasm are associated with aggressive humor. This style "relates to the tendency to express humor without regard for its potential impact on others" (Martin et al., 2003, p. 54). Sexist and racist humor are common in this humor style, and this type of humor is typically compulsive. Aggressive humor is connected to neuroticism and has a negative relationship with agreeableness and conscientiousness.

A good example of aggressive humor is seen in the ongoing bickering and pranking between Tim and Gareth in the UK version of the show. In the first episode of season one, "Downsize," (Gervais \& Merchant, 2001), this is first shown to the audience. In the episode, Tim places Gareth's stapler inside of Jell-O because Tim knows that Gareth has an aversion to the jelly. Later in the same episode, Tim builds a "wall" between his and Gareth's desks, and proceeds to pretend that if he cannot see Gareth, then he cannot hear him either. Gareth grows increasingly irritated with Tim's pranks, but this does not stop him. Acting compulsively and without regard for Gareth's feelings is supported by the literature (Martin et al., 2003) as being aggressive humor.

\section{Self-defeating humor.}

Self-defeating humor "involves excessively self-disparaging humor, attempts to amuse others by doing or saying funny things at one's own expense, or allowing oneself to be the "butt" of other's humor, as a means of integrating oneself or gaining approval..." (Martin et al., 2003, p. 54). This type of humor is often used to avoid feeling underlying levels of self-consciousness and has elements of neediness. Therefore, this humor style is positively related to neuroticism. 
For example, David Brent in the UK series often engages in self-defeating humor in order to gain the approval his friend Chris Finch. In the season one episode "The Quiz" (Gervais \& Merchant, 2001), Finch enters and jokes with David about hit weight, saying there isn't a seatbelt large enough to fit around him. David replies by laughing and saying "all bought and paid for," thus continuing the joke at his own expense. Finch then continues by mocking David's sexuality, which David again responds to in a selfdisparaging manner. This scene is not acted out in a necessarily friendly manner; Finch's jokes are on the aggressive side, while David's jokes seem desperate to make Finch like him. Such behavior is backed by existing research (Martin et al., 2003) as being selfdefeating humor.

\section{The Big Five}

As previously mentioned, each of the four humor styles is associated with a personality trait(s). The idea that certain personality traits are common among members of a particular culture is referred to as national character or national stereotypes (McCrae \& Teracciano, 2006, p. 156). Such stereotypes are thought to be "generalizations based on observations of the personality traits of individual culture members" (Terracciano et al., 2005, p. 96). While national culture or national stereotypes may be overgeneralizations of entire cultures, a theory termed the "kernel of truth" hypothesis suggests that there is validity to stereotypes because perceptual processes are likely to identify and exaggerate differences between groups over time (LeVine \& Campbell, 1972). Terracciano et al. (2005) refer to culture as being a social construct, while "personality traits are rooted in biology" (p. 96). Personality traits can be defined as the unique disposition of an individual that leads to certain behavioral patterns (Junglas, 
Johnson \& Spitzmüller, 2008, p. 391). These patterns often vary depending on what is appropriate behavior for the culture, which is known as "cultural personality" (Nazir, Enz, Lim, Aylett, \& Cawsey, 2009, p. 284). One study claims that aggregate personality scores can be established for each country but do vary depending on culture and exhibit only interpretable correlations (Peele \& Kadekar, 2002, p. 124). For the purposes of this study, the term national personality will be used to describe the overall personality of a country based upon existing research that depicts how the people of a nation tend to have similar biological traits, and thus similar personality traits.

Personality psychologists agree that the five-factor model (FFM), also known as the Big Five, accounts for most correlated variations of personality and has "brought clarity to the domain of personality" (Digman, 1990, p. 418). One study concluded that its findings show "the general contours of the Big Five model as the best working hypothesis of an omnipresent trait structure” (De Raad, Blas \& Perugini, 1998, p. 40). The FFM is comprised of five factors: openness, conscientiousness, extraversion, agreeableness, and neuroticism.

Early research into personality traits resulted in confusion and competing ideas, such as those of Cattell's 16 Personality Factor Questionnaire (Cattell \& Eber, 1962) and Eysneck's PEN or Gigantic Three (Maher \& Maher, 1994, p. 75). The inconsistencies of personality analysis were rectified in 1961 when Tupes and Christal (1992) found five recurrent traits among eight different samples (p. 232). These five factors were surgency, agreeableness, dependability, emotional stability, and culture (Tupes \& Christal, 1992, pp. 233-244). These five traits do not necessarily indicate that there are only five dimensions of personality, though, but rather "represent personality at the broadest level 
of abstraction" (John \& Srivastava, 1999, p. 105).

One of the most notable contributors to the FFM model was Warren Norman (1967), who conducted a study in the 1960s that aimed to develop an exhaustive, "wellstructured taxonomy of personality descriptive terms" (p. 1). This "Big Five" model is "the system that appears to have won the vote of most differential psychologists" (Company, 2013, p. 30). Therefore, this study will use the FFM as the basis for analysis in the respective personalities of the UK and the U.S. in concurrence with the four humor styles to see how these personality traits interact with the interpretation of humor when applied to adapted television shows.

Norman (1967) based his procedures upon earlier research to determine 2,800 terms sorted into 75 semantic categories relevant to biophysical personality traits. These 2,800 terms were then divided into lists and distributed to numerous random samples to obtain peer ratings. Norman, too, found five dominant traits from his research, but while these five were nearly identical to Tupes and Christal's five, Norman named the five categories as follows: openness, conscientiousness, extraversion, agreeableness, and neuroticism, each of which will be further discussed below. The research of these contributors, particularly Norman, has been replicated by a vast number of studies, thus these five factors "have been shown to have good validity and reliability across research studies, varying populations, and spanning several decades” (Company, 2013, p. 30).

\section{Openness.}

Openness is the equivalent to Tupes and Christal's culture. It refers to an individual's receptivity to experience and is sometimes the intellect trait. Those who have high levels of openness are likely to have a wide range of interests and to be imaginative 
(Srivastava, 2015). Originality and open-mindedness are words often associated with this trait. In a study on personality, John, Naumann, and Soto (2008) define openness as "the breadth, depth, originality, and complexity of an individual's mental and experiential life" (p. 120). On the other hand, closed people tend to be conservative, traditional, and opposed to change (Tamkins, 2007).

\section{Conscientiousness.}

Control is a key element of conscientiousness. John et al. (2008) found this trait to be a "socially prescribed impulse control that facilitates task- and goal-directed behavior..." (p. 120). Individuals who possess this trait are likely to be organized and thorough (Srivastava, 2015). Conscientiousness is the equivalent to Tupes and Christal's dependability, and self-discipline and reliability and words associated with this trait (John, Naumann \& Soto, 2008, p. 126). Those who possess low levels of conscientiousness tend to have little ambition and may find it difficult to achieve goals (Tamkins, 2007).

\section{Extraversion.}

Extraversion, or called surgency in Tupes and Christal's findings, exemplifies characteristics of talkativeness, energy, and assertiveness (Srivastava, 2015). This trait "implies an energetic approach toward the social and material world" and includes traits such as sociability and positive emotionality (John et al., 2008, p. 120). In contrast, introverts "are less prone to feeling positive emotions" but are not necessarily more prone to negative emotions (Tamkins, 2007). Introverts are often quiet and reserved in comparison to their extravert counterparts. 


\section{Agreeableness.}

John et al. (2008) say that agreeableness "contrasts a prosocial and communal orientation toward others with antagonism..." (p. 120). Individuals with high levels of agreeableness are likely to be modest, altruistic, sympathy, and kindness (John et al., 2008, p. 120; Srivastava, 2015). Disagreeable people are more self-centered and may be skeptical of other people (Tamkins, 2007).

\section{Neuroticism.}

Neuroticism is the antonym to Tupes and Christal's emotional stability. Individuals who possess this trait can be described as being moody (Srivastava, 2015). This trait is associated with "negative emotionality, such as feeling anxious, nervous, sad and tense" (John et al., 2008, p. 120). Low neuroticism people are less likely to experience these negative emotions but not necessarily more likely to experience positive emotions. Individuals with low levels of neuroticism tend to be more emotionally stable (Tamkins, 2007).

\section{Personality and Communication.}

Just as humor and communication are closely linked, the same can be said of personality and communication. McCrae and Costa (1999) drew upon the FFM to create the five-factor theory (FFT). The researchers propose the biological bases are what influence personality. Personality is "the dynamic psychological organization that coordinates experience and action" (McCrae \& Costa, 1999, p. 162). This organization is comprised of personality traits, which are "individual-difference variables" (McCrae \& Costa, 1999, p. 162). These personality traits fall under the umbrella of the Big Five: openness, conscientiousness, extraversion, agreeableness, and neuroticism, as previously 
discussed. "These basic tendencies are specific to each person, stable across time, and largely inheritable" (Waldherr \& Muck, 2011, p. 8).

Waldherr and Muck (2011) present the idea that communication styles are influenced by personality by applying the FFT to communication theory (p. 8). The researchers write, "When applying the FFT to communication theory, communication styles may be interpreted as characteristic adaptations. This would acknowledge that communication styles are characteristic and relatively stable behavioral patterns but influenced by personality, which is in turn dependent on individual biological bases" (Waldherr \& Muck, 2011, p. 8). This then suggests that communication styles are dependent upon an individual's unique personality.

The theory then proposed by Waldherr and Muck (2011) is as follows:

"Communication styles are characteristic adaptations of personality and describe the way one verbally and nonverbally interacts with others" (p. 10). The communication process of humor involves a message being sent out and how that message is received and interpreted. Lynch (2002) proposes that there are two main parts to the communication process of humor: rhetorical studies and examinations of the social functions of messages (p. 430). The rhetorical component of communication studies aims to persuade the audience to be amused by the message. The social function of humor, on the other hand, reflects one's ability to use and recognize humor and essential to success in social situations (Lynch, 2002, p. 432).

\section{Brits vs. Americans.}

This study will examine the humor and communication styles of two countries, the UK and the U.S. A look into common stereotypes of the U.S. has left Americans 
commonly labeled as being two things: loud and obnoxious. This stereotype is so common, in fact, that one Irish café went as far as to post a sign that read "No loud Americans" (Loud Americans? Not Here, Thanks, 2014). An extreme example of the American stereotype is seen most recently in Donald Trump. Adam LeBor (2015) writes that the ostentatious Trump "hits every negative stereotype of Americans that Europeans love to hate" (p. 1). While these stereotypes are perhaps an overgeneralization of the population, the American people do, for the majority, possess personality traits that support these clichés.

Brits, on the other hand, are often thought to be snobbish and reserved. A book written by Julian Fellowes called Snobs, released in 2004, centers around this British stereotype and discusses how snobbery still exists in the country's modern culture (Mount, 2004). Again, existing research indicates that there is some merit to these stereotypes. With these differences in mind, it is logical to assume that the humor of these two nations is different, and not just in terms of spelling.

Although the social structure of the UK has changed over the centuries, class differences still play a role in the country's humor. Sexual humor is also widespread, as well as a focus on "the mundane reality by satirically revealing the absurdity of everyday life, relying largely on puns and intellectual humor" (Attardo, 2014, p. 542). Ricky Gervais, who co-wrote, co-produced, and starred in the UK version of The Office wrote an article for TIME about the differences between American and British humor, particularly those found between the two series. "Brits are more comfortable with life's losers. We embrace the underdog until it's no longer the underdog. ... We don't want to celebrate anything too soon. Failure and disappointment lurk around every corner. This is 
due to our upbringing. Americans are brought up to believe they can be the next president of the United States. Brits are told, 'It won't happen for you.' " (Gervais, 2011). The British are brash; irony, sarcasm, and misery are as central to the country's humor as tea is to the culture.

Americans perhaps have a more optimistic outlook on life, which has shaped a unique humor type throughout the country. While elements of sarcasm and irony are still present in American humor, the country has channeled these types of humor into different lines of communication in order to continue reaching the popular audience (Hill, 1963, p. 170). The American people "applaud ambition and openly reward success" (Gervais, 2011), meaning that the country enjoys watching the nice guy or cheering on the clear winner. Gervais notes this being the reason why David Brent (UK version) and Michael Scott (U.S. version) have contrasting levels of malice. Scott, who was based upon Brent's character, retains elements of childishness and insecurity but possesses a more pleasant disposition. Scott often shows more remorse than Brent and is portrayed as being somewhat clueless if he is hurting another character's feelings.

A further look into the stereotypes of various cultures provides an interesting insight into the differences between the British and Americans. In one study (Prothro \& Melikian, 1955), subjects were presented with a list of 99 adjectives and were asked to select which ones best described various cultures. The following words were associated with the stereotypical Brit: intelligent, selfish, hypocritical, shrewd, and egotistic. The words most commonly associated with Americans were sociable, superficial, jolly, and simple (Prothro \& Melikian, 1955, p. 7). Word association allows for the aligning of these words with the Big Five to speculate the national personality of each respective 
country.

To supplement this idea, McCrae and Terracciano (2005) conducted a study that evaluated personality traits across 50 different cultures to establish a mean for each of the FFM traits in all countries analyzed. The results suggested the UK is more neurotic and more open than the U.S., while the U.S. is more extraverted. Both the UK and the U.S. were highly agreeable and highly conscientious (McCrae \& Terracciano, 2005, p. 558). This information will be used to form this researcher's hypotheses by comparing which of the FFM traits are more dominant in each country and assuming that the corresponding humor style will occur more frequently in that country's version of the sitcom. This study then seeks to determine if these noted differences in culture and humor are truly enough to be evident in a TV series that essentially follows the same story line.

\section{Research Hypotheses}

The purpose of this study is to explore whether differences exist between the U.S. and the UK's humorous TV sitcom The Office by conducting a content analysis of humor styles. By relying on previous studies that have determined the personality traits that separate these two countries and associating these differences with Martin et al.'s (2003) four humor styles, this study identifies the humor styles employed in each country and discusses how national personality can potentially influence the use of each of these humor styles.

\section{Personality Trait Differences}

As previously discussed, existing research has identified five primary dimensions of personality: openness, conscientiousness, extraversion, agreeableness, and neuroticism. Studies that have examined geographic personality traits in the UK and U.S. 
reveal that the two countries are most divergent on three of these five personality traits: extraversion, neuroticism, and openness. The remaining two personality traits, agreeableness and conscientiousness, were approximately equally prominent in both the UK and the U.S.

\section{Affiliative Humor and National Personality}

The purpose of the affiliative humor style is to find a way to approach and create a bond with others by amusing them. "The affiliative humor style reflects jokes and flirts in a social setting where the humor initiators have the tendency to say funny things or use some self-deprecating stories" (Cruthirds et al., 2012, p. 389). It is related to social intimacy and extraversion, so based upon the knowledge that the U.S. has higher levels of extraversion than the UK (McCrae \& Terracciano, 2005, p. 558), it can be assumed that the U.S. will be more likely to use affiliative humor.

H1. The U.S. version of The Office will use more affiliative humor than the UK.

\section{Self-enhancing Humor and National Personality}

Self-enhancing humor is used to "keep a generally positive outlook on life" (Cruthirds et al., 2012, p. 390). This humor style is associated with openness, extraversion, agreeableness, and conscientiousness. While the U.S. has higher levels of extraversion, the UK has higher levels of openness throughout its nation. As was mentioned earlier, both countries have approximately the same levels of agreeableness and conscientiousness (McCrae \& Terracciano, 2005, p. 558), so it seems that each country would use a similar degree of self-enhancing humor in television sitcoms.

H2. A similar amount of self-enhancing humor will be used in the UK and U.S. 
versions of The Office.

\section{Aggressive Humor and National Personality}

Disparagement humor and putting others down are central to aggressive humor. This style of humor is linked to neuroticism. The UK has higher levels of neuroticism than the U.S. (McCrae \& Terracciano, 2005, p. 558), so it is likely that British humor will be more likely to draw upon aggressive humor to gain laughs.

H3. The UK version of the The Office will use more aggressive humor than the U.S.

\section{Self-defeating Humor and National Personality}

Acting in a self-disparaging manner and seeming to possess low self-esteem are often associated with self-defeating humor (Cruthard et al., 2012, p. 391). Since selfdefeating humor is linked to neuroticism and the UK has a higher degree of neuroticism than the U.S. (McCrae \& Terracciano, 2005, p. 558), the argument presented in this research suggests that self-defeating humor is used more in the UK.

H4. The UK version of the The Office will use more self-defeating humor than the U.S.

\section{Methodology}

If humor is to be viewed as a communication process, Wadherr and Muck's (2011) application of the FFT to communication theory that proposes that personality influences communication therefore can be applied. The current research suggests that personality is a factor when interpreting humor in television sitcoms, thus influencing the prominent types of humor styles used in different cultures. 


\section{Sample}

In order to obtain a sizable sample of the types of humor used in both the UK and U.S. versions of The Office, the sample consisted of 14 episodes from each version that were analyzed using content analysis. This number was selected because the UK version of The Office offers only two seasons, while the U.S. version offers nine; due to this limitation, the sample will be tailored to include all episodes from the UK version, and that figure then has dictated the number of episodes to be used from the U.S. adaptation. Both versions contain only six episodes in the first season that were analyzed. The second season of the UK version then contains eight episodes, providing the limit of 14 episodes. While the second season of the U.S. version contains 22 episodes, only the first eight episodes were analyzed. The sample was accessed through Netflix and each episode is an average of 25 minutes in length.

\section{Coding Procedure}

Two American coders were used in the content analysis to ensure reliability; the researcher acted as one of these coders. Each episode was broken down into character sequences and confessional sequences by the coders, who then identified the humor styles represented in each sequence. Looney (2012) defines a character sequence as "any thematically continuous scene between one or more characters" and a confessional sequence as "any scene in which the character is addressing the camera, usually alone, in a confessional manner" (p. 19). This method was used because the analysis was intended to detect humor in overall themes of the episodes, as opposed to focusing on individual characters.

The coders watched each episode through an initial time to determine a unit of 
measurement in character sequences and confessional sequences. From the 28 total episodes, 433 character sequences and confessional sequences were established, with 162 sequences occurring in the U.S. version and 271 sequences occurring in the UK version. The UK episodes were on average 6 minutes longer than the U.S. episodes, which may possibly account for the discrepancy in number of sequences.

After sequences were established, each coder was asked to view all 28 episodes a second time and to apply the four humor styles identified by Martin et al. (2003). More than one humor style may have been present in a single continuous character sequence or confessional sequence. In order to reduce subjectivity, the coders were instructed to code each sequence on whether or not there was intended humor, as opposed to giving their opinion on the humorousness.

The coders were rigorously trained in identifying the characteristics of the four humor styles. Various sketches performed by a diverse set of 15 comedians were selected to aid in the training. Each performance was played one at a time and repeated if necessary in order for the inter-coders to form an opinion on the humor style being represented. A standard coding form was used to evaluate each comedian. When a 0.75 agreement was reached between coders, the training was regarded as successful.

Humor style inter-coder reliability was calculated using Cohen's kappa because this is the most commonly used statistic for the purpose of measuring agreement and disagreement levels between two or more observers (Viera \& Garrett, 2005, p. 360). A systematic sample of 50 sequences, either character or confessional, were chosen by selecting every eighth data set within the 433 total sequences for each coder. This was done to ensure both versions of The Office were tested for inter-coder reliability. The 
inter-coder reliability for each of the four humor styles reached above 0.85 , which is the threshold Kassarjian (1977) suggests as satisfiable for intercoder reliability for content analyses (p. 14). For self-enhancing humor, the measure of agreement was 0.88 ; the measure of agreement for affiliative humor was also 0.88; aggressive humor reached 0.89 agreement; and self-defeating humor reached 0.90 .

\section{Results}

After the data was gathered, a statistical comparison using chi-square analysis was conducted on each humor style individually, comparing the UK and U.S. versions of The Office. Significance was set at $p<.05$ for all procedures. The statistical results comparing the four types of humor styles are summarized in Table I.

\begin{tabular}{|c|c|c|c|c|c|c|}
\hline Humor Style & $\begin{array}{l}\text { U.S. } \\
\text { Frequency }\end{array}$ & $\begin{array}{l}\text { Percentage } \\
(n=162)\end{array}$ & $\begin{array}{l}\text { UK } \\
\text { Frequency }\end{array}$ & $\begin{array}{l}\text { Percentage } \\
(\mathrm{n}=271)\end{array}$ & $x^{2}$ & $p$ \\
\hline Affiliative & $96 * * *$ & $59 \%$ & 98 & $36 \%$ & 24.119 & .000 \\
\hline Self-enhancing & 58 & $36 \%$ & 123 & $45 \%$ & 3.683 & .159 \\
\hline Aggressive & 60 & $37 \%$ & $155 * * *$ & $57 \%$ & 17.773 & .000 \\
\hline Self-defeating & 12 & $8 \%$ & $47 * *$ & $17 \%$ & 10.502 & .005 \\
\hline$* * p<.01, * * * p<$ & & & & & \multirow{2}{*}{\multicolumn{2}{|c|}{$\begin{array}{l}\text { Table I. } \\
\text { Statistical results }\end{array}$}} \\
\hline $\begin{array}{l}\text { Note: More than o } \\
\text { in a single characte } \\
\text { to this, aggregate } p\end{array}$ & $\begin{array}{l}\text { umor style ma } \\
\text { quence or con } \\
\text { entages will ex }\end{array}$ & $\begin{array}{l}\text { have been det } \\
\text { ssional sequer } \\
\text { ed } 100 \% \text {. }\end{array}$ & & & & \\
\hline
\end{tabular}

The first hypothesis predicted that the U.S. version of The Office uses more affiliative humor than the UK version. Ninety-six out of 162 sequences observed in the U.S. version of The Office used affiliative humor, compared to 98 out of 271 used in the UK version. These differences were significant $\left(x^{2}=24.119, p<.05\right)$. This result indicated that the U.S. version of The Office was more likely to use affiliative humor. 
Therefore, $H 1$ was supported. Affiliative humor was also used more than any of the other humor styles within the U.S. version.

The second hypothesis predicted that there would be no significant difference in the amount of self-enhancing humor employed in the two versions. Self-enhancing humor occurred in 58 out of the 162 sequences throughout the U.S. version and in 123 out of 271 of the sequences in the UK version. Taking into consideration a larger total of sequences in the UK version, the percentage was non-significant $\left(x^{2}=3.683, p>.05\right)$. The result indicated that the two versions utilized a similar amount of self-enhancing humor. $H 2$ was supported.

It was predicted that the UK version would use more aggressive humor than the U.S. version in H3. The UK version employed aggressive humor more than any other humor style, with it being observed in 155 out of 271 sequences; aggressive humor was observed in 60 out of 162 sequences in the U.S. version. Statistical analysis showed that the difference in percentages was significant $\left(x^{2}=17.773, p<.05\right)$. Based upon these results, $H 3$ was supported.

The final hypothesis predicted that self-defeating humor would be used more in the UK version than the U.S. version, and was supported as expected. Self-defeating humor was found in 47 of the 271 sequences in the UK version and in only 12 out of the 162 sequences in the U.S. version $\left(x^{2}=10.502, p<.05\right)$. However, self-defeating humor was the least common humor style in both versions.

\section{Discussion}

In summary, four out of four hypotheses were supported. These findings indicate the possibility of humor styles differing from country to country, which would then 
suggest that reculturalization is indeed a necessary factor when adapting a television program (Della Colletta, 2012, p.2). While limited to one set of data, the notion of these findings can offer valuable insights to researchers and practitioners engaging in crosscultural adaptation.

The statistical analysis in this study showed that there are significant differences between the humor styles utilized in the two versions of The Office, despite the similarity in storyline. By examining dominant personality traits as determinants of humor styles, the findings show that the U.S. was more inclined to use affiliative humor as the preferred humor style in the examined sitcom, possibly demonstrating predilections resulting from the nation's culture and extraverted personality (McCrae \& Terracciano, 2005, p. 558). Likewise, aggressive and self-defeating humor are used more in the UK version than the U.S. version, possibly reflecting the country's neurotic personality (McCrae \& Terracciano, 2005, p. 558) and cultural make-up.

The current research benchmarked the frequency of humor styles in one adapted sitcom that aired in the UK and the U.S. Through the application of the FFT (McCrae \& Costa, 1999), the findings help to depict the different types of humor that are optimally employed in a sitcom that aired in two countries with differing cultures and personalities. The researcher argues that reculturalization to fit specific personality and cultural differences was a necessary factor when adapting The Office from the British market to the American market. Reculturalization focuses on the response that the adapted material will receive and thus is open to make necessary changes to receive the best response, as opposed to merely translating something for a new audience but not diverting too much from the original (Hutchings \& Vernitski, 2005). The U.S. version of The Office was 
willing to deviate away from the prominent aggressive humor style seen in the UK version and use more affiliative humor instead, likely hoping to receive a more positive response from the target audience.

Existing research has found that in addition to cultural factors, physical and social contexts also affect the linguistic choices made in adaptation (Ma \& Jiang, 2013). Pop culture references serve as an example of such contexts that vary from country to country and need to be altered to fit the audience, or the intended humor may be lost in translation. Furthermore, different humor style preferences can cause misunderstanding of the message intent and result in problems for television producers hoping to successfully adapt a show from one market to another (Cruthirds et al., 2011, p. 384). For example, the popular British sitcom Spaced, which first aired in the UK in 1999 and garnered several awards throughout its two-series run, failed in its attempt to translate British humor to the American market in the 2007 adaptation. FOX shelved the show before it even aired on the network. Edgar Wright, director of the UK version of Spaced, commented that the American version was "impossible to make and that translating and sanitizing it for American audiences wouldn’t make much sense” (Thomas, 2011).

The Office did not attempt to give the American audience the exact same type of humor that was given to the UK market; instead, the producers and writers found a way to translate the intent of the show in a way that would appeal to U.S. market, and shifting the main humor style used seems to have been one reason for its success. British humor tends to have a quality of understatement about it (Asscher, 2010, p. 240), and Ted Harbert, who was president at NBC when The Office was being adapted for the U.S. market, noted that "the smaller and smarter joke[s]" had to be replaced with "bigger and 
more obvious comedy" (Masters, 2005).

The conclusions from this research could possibly enable producers to make wellplanned decisions when adapting television shows for a different country. Knowing the style of humor that may be preferred in different countries gives producers working on adaptations an edge by incorporating the most popular humor style for that culture. This could help lead to fewer failures and more successful adaptations between countries. The UK version of The Office was much more satiric and bleak, while the U.S. version focused more so on character comedy, which is where actors base the characters upon themselves (Ducray, 2012). As the actors in the U.S. version were Americans, it seems viable that the use of character comedy allowed the sitcom to be more palatable to the U.S. audience. The contrast between the bleak David Brent of the UK version and the over-the-top Michael Scott of the U.S. version are clear examples of the satirical humor used in the British version as opposed to the slapstick comedy of the American version (Ducray, 2012).

The findings of this research help to further the application of the FFT (five-factor theory) to communication theory (Waldherr \& Muck, 2011) by explicitly examining humor as a communication medium. The findings presented will add to the body of knowledge regarding humor in television adaptations by showing cultures as fundamentally different entities shaped by individuals' personality traits, that then in turn shape countries' humor preferences. This research also advances the credibility of the kernel of truth theory (LeVine \& Campbell, 1972) by supporting the idea that the stereotypes of specific cultures can and do shape the people and their preferences, specifically humor preferences in this observed case. 
If cultural and personality trait differences between countries are ignored, the results could be catastrophic. This research only listed a few of the numerous failed adaptations from the UK market to the U.S. market. The unique success of the adaptation of The Office has been explored in previous research (Looney, 2012; Griffin, 2008). Beyond the findings of the cultural angles in these studies, this research reveals the impact that personality has on humorous adaptations and how they are sometimes interpreted and received by viewers of a particular country.

\section{Limitations and Future Research}

The findings of this research should be interpreted with caution for several reasons. First, this study is only one of many televisions series that have been adapted from one market to another. Based on this single sampling frame, it may not be feasible to generalize national personality based upon the most prevalent humor styles observed. The adaptation of the series also serves as a limitation itself; The Office was originally a British television show intended for British people, making the U.S. version a British sitcom modified for Americans. Each series also aired on different channels on separate television systems and aired during different years, which can influence the format and type of content based on several factors, such as media policies, budgets, and production values (Zwaan \& Bruin, 2012, p. 28).

Both coders utilized in this study were American; British coders may have detected certain nuances within the UK series that may have been missed by the American coders. Personal taste of American coders may have also resulted in bias, causing some humor in the UK version to be missed. Gervais (2011) pointed out that in his experience, he found that Americans need a reason to like the characters, while Brits are more compelled by 
the "doom and gloom" of villainy. Since the U.S. version contains seven seasons beyond what was analyzed in the current research, an important direction for this research vein would be to examine the U.S. sitcom in its entirety to determine if the prominent humor styles continued throughout the series.

Although differences in humor styles used in the television sitcom The Office were found, this study was strictly based on the UK and the U.S., which despite some distinctions, do have similar cultures, and thus the results may not necessarily be applicable to the adaptation of TV shows as a whole. However, the similar cultures may have eliminated other influencing factors other than personality and culture such as economic levels or religious beliefs as potential explanations for the differences in humor styles. An important direction for this research would still be to examine other series that have been adapted in more divergent cultures, particularly non-Western cultures with lower levels of individualism (Peele \& Kadekar, 2007, p. 123), to support the idea that personality and culture influence humor preferences. This line of research can also be made more effective by evaluating more sitcoms that have been adapted from the UK market to the American market, which could provide insight as whether humor and personality affects the success or failure of adaptations.

The ideas proposed in this research can be better supported through the collection and analysis of humor styles through the administration of the Humor Styles Questionnaire (Martin et al., 2003) and a collection of dominant personality types through the administration of the Big Five Inventory (BFI-44) (John, Donahue \& Kentle, 1991) in broad areas of both countries. This would enable researchers to determine if a correlation does exist between national personality and the humor preferences of a 
country.

\section{Conclusion}

From the above analysis, it can be concluded that culture and personality do have explanatory power and feasibility on the analysis of the adaptation of humor in the sitcom The Office. Both the UK and U.S. versions of the sitcom experienced success within their own markets. The current research attributes some of this success to the reculturalization that occurred in several aspects of the adapted version, specifically the prominent humor style used. This research also attempts to highlight the role of personality in understanding humor and how it translates to audiences within a specific country. It is clear that the changes made in the U.S. version of the show illustrate how national identity and overall personality is a "vital part" of adaptation (Beeden \& de Bruin, 2009).

It is understandable why this is such an important strategy for the success of an adapted sitcom when examining humor as a preference shaped by a country's culture and dominant personality traits, as is consistent with the cross-cultural adaptation theory (Young, 2001). The current research supports Young's (2001) idea that individuals and their traits that are in the same environment, or country, can be examined as a collective, large entity to identify preferences of the whole. This was done through the analysis of both the UK version and the U.S. version of The Office to categorize and identify which of Martin et. al.'s (2003) four humor styles was more prominent in each version. This research hypothesized that the dominant humor style used in each respective country's version would correlate to the specific personality trait that McCrae and Terracciano (2005) found to be chiefly associated with each country (p. 558). The results then supported the link between personality and humor that Martin et al. (2003) proposed, 
given the findings of statistically significant differences between affiliative humor, which is associated with extraversion, being used more in the U.S. version and aggressive humor, which is linked to neuroticism, being used more in the UK version. 


\section{References}

Loud Americans? Not Here, Thanks. (2014). Calgary Herald.

Alden, D. L., Mukherjee, A., \& Hoyer, W. D. (2000). The effects of incongruity, surprise and positive moderators on perceived humor in television advertising. Journal of Advertising, 29(2), 1-15.

Allik, J. (2006). Personality dimensions across cultures. Dimensional Models of Personality Disorders: Refining the Research Agenda for DSM-V, 117.

Asscher, O. (2010). A model for hebrew translation of british humor: Amplification and overstatement. Target: International Journal of Translation Studies, 22(2), 237263. doi:10.1075/target.22.2.04ass

Attardo, S. (2014). National and Ethnic Differences. In Encyclopedia of humor studies. Thousand Oaks, California: SAGE Publications.

Beeden, A. \& de Bruin, J. (2009). The Office: Articulations of national identity in television format adaptation. Television \& New Media, 11(1), 3-19.

Bell, J. (n.d.). 10 Failed American Remakes of British Sitcoms. Retrieved March 16, 2016, from http://tvcomedies.about.com/od/listsrecommendations/tp/10-FailedAmerican-Remakes-Of-British-Sitcoms.htm

Cattell, R., and Eber, H. (1962). Handbook for the sixteen personality factor questionnaire, "The 16 P.F. Test" forms A, B, and C (1957 ed.). Champaign, Ill.: Institute for Personality and Ability Testing.

Cohen, B. B. (1927). THE GAG BECOMES BIG BUSINESS: Machine-made for the theatre, it is sold by specialists in humor GAG-MAKING A BIG BUSINESS. The New York Times 
Collins, R., \& American Council of Learned Societies. (1990).Culture, communication and national identity: The case of canadian television. Toronto: University of Toronto Press. doi:10.3138/j.ctt2tv53r

Company, S. (2013). Psych 101 Series Sampler Introductions to Key Topics in Psychology. New York: Springer Publishing Company.

Cruthirds, K. W., Wang, V. L., Wang, Y. J., and Wei, J. (2012). A comparison of humor styles in US and mexican television commercials. Marketing Intelligence and Planning, 30(4), 384-401. doi:10.1108/02634501211231856

Daniels, D. (Writer and Director). (2005). Basketball. In D. Daniels (Producer), The Office. Los Angeles, California: Chandler Valley Center Studios.

De Raad, B., Di Blas, L., and Perugini, M. (1998). Two independently constructed Italian trait taxonomies: comparisons among Italian and between Italian and Germanic Languages. European Journal Of Personality, 12(1), 19-41.

Della Coletta, C., \& ebrary, I. (2012). When stories travel: Cross-cultural encounters between fiction and film. Baltimore, Md: Johns Hopkins University Press.

Digman, J. M. (1990). Personality structure: Emergence of the five-factor model. Annual Review of Psychology, 41(1), 417-440. doi:10.1146/annurev.ps.41.020190.002221

Ducray, A. (2012). Sharing the joke? 'britcom' remakes in the united states: a historical and socio-cultural perspective. The French Journal of Media and Media Representations in the English-Speaking World.

Friedman, S. (2011). The cultural currency of a 'good' sense of humour: British comedy and new forms of distinction.The British Journal of Sociology, 62(2), 347-370. 
doi:10.1111/j.1468-4446.2011.01368.x

Gervais, R. (2011, November 9). The Difference Between American and British Humour. Time.

Gervais, R., \& Merchant, S. (Writers and Directors). (2001). Downsize. In A. Atalla (Producer), The Office. United Kingdom: British Broadcasting Corporation.

Gervais, R., \& Merchant, S. (Writers and Directors). (2001). The quiz. In A. Atalla (Producer), The Office. United Kingdom: British Broadcasting Corporation.

Griffin, J. (2008). The americanization of the office: A comparison of the offbeat NBC sitcom and its british predecessor. Journal of Popular Film and Television, 35(4), 154-163. doi:10.3200/JPFT.35.4.154-163

Hill, H. (1963). Modern American Humor: The Janus Laugh. College English, 170-176. doi: $10.2307 / 373683$

Howe, N. E. (2002). The origin of humor. Medical Hypotheses, 59(3), 252-254. doi:10.1016/S0306-9877(02)00209-8

Hutchings, S. C., \& Vernitski, A. (2005). Russian and soviet film adaptations of literature, 1900-2001: Screening the word. New York;London;: Routledge.

John, O. P., Donahue, E. M., \& Kentle, R. L. (1991). The Big Five Inventory-Versions 4a and 54. Berkeley, CA: University of California, Berkeley, Institute of Personality and Social Research.

John, O., Naumann, L., and Soto, C. (2008). Paradigm Shift to the Integrative Big Five Trait Taxonomy. In Handbook of personality: Theory and research (3rd ed.). New York: Guilford Press. 
John, O., and Srivastava, S. (1999). The big-five trait taxonomy history, measurement, and theoretical perspectives. Berkeley, CA: University of California.

Junglas, I. A., Johnson, N. A., and Spitzmüller, C. (2008). Personality traits and concern for privacy: An empirical study in the context of location-based services. European Journal of Information Systems, 17(4), 387-402. doi:http://dx.doi.org/10.1057/ejis.2008.29

Kalliny, M., Cruthirds, K. W., \& Minor, M. S. (2006). Differences between american, egyptian and lebanese humor styles: Implications for international management.International Journal of Cross Cultural Management, 6(1), 121-134. doi:10.1177/1470595806062354

Kassarjian, H. H. (1977). Content analysis in consumer research. Journal of Consumer Research, 4(1), 8-18. doi:10.1086/208674

Landy, M. (2005). Monty Python's flying circus. Detroit: Wayne State University Press.

LeBor, A. (2015, ). Donald trump: The american stereotype europeans love to hate. Newsweek

LeVine, R.A., and Campbell, D.T. (1972). Ethnocentrism. New York: Wiley. Nazir, A., Enz, S., Lim, M. Y., Aylett, R., \& Cawsey, A. (2009). Culture-personality based affective model. AI \& Society, 24(3), 281-293. doi:10.1007/s00146-009$0217-2$ 
Novak, B.J. (Writer). (2005). The fire. In D. Daniels (Producer), The Office. Los Angeles, California: Chandler Valley Center Studios.

Norman, W. (1967). 2800 personality trait descriptors: Normative operating characteristics for a university population. Ann Arbor: University of Michigan, Dept. of Psychology.

Looney, M. M. (2012). Humor vs. humour in "the office": The necessary adaption of television humor from the british market to the american market.

Lynch, O. H. (2002). Humorous communication: Finding a place for humor in communication research. Communication Theory, 12(4), 423-445. doi:10.1093/ct/12.4.423

Ma, Z., \& Jiang, M. (2013). Interpretation of verbal humor in the sitcom the big bang theory from the perspective of adaptation-relevance theory. Theory and Practice in Language Studies, 3(12), 2220. doi:10.4304/tpls.3.12.2220-2226

Maher, B. A., \& Maher, W. B. (1994). Personality and psychopathology: A historical perspective. Journal of Abnormal Psychology, 103(1), 72-77. doi:10.1037/0021843X.103.1.72

Martin, R. A., Puhlik-Doris, P., Larsen, G., Gray, J., and Weir, K. (2003). Individual differences in uses of humor and their relation to psychological well-being: Development of the humor styles questionnaire. Journal of Research in Personality, 37(1), 48-75. doi:10.1016/S0092-6566(02)00534-2

Masters, K. (2005, March 24). British tv crosses over the pond. NPR News: Morning 
Edition. Retrieved from

http://www.npr.org/templates/story/story.php?storyId=4558607

McCrae, R., and Costa, P. (1999). The Five-Factor Theory of Personality. In Handbook of personality: Theory and research (2nd ed.). New York: Guilford Press.

McCrae, R. R., Terracciano, A., Personal Profiles Cultures Project, Personality Profiles of Cultures Project, and Members of the Personality Profiles of Cultures Project. (2005). Universal features of personality traits from the observer's perspective: Data from 50 cultures. Journal of Personality and Social Psychology, 88(3), 547561. doi:10.1037/0022-3514.88.3.547

McCrae, R. R., \& Terracciano, A.. (2006). National Character and Personality. Current Directions in Psychological Science, 15(4), 156-161. Retrieved from http://www.jstor.org/stable/20183103

McGraw, P. (2011, September 14). The Importance of Humor Research. Retrieved November 11, 2015, from https://www.psychologytoday.com/blog/the-humorcode/201109/the-importance-humor-research

Meyer, J. C. (2000). Humor as a Double-Edged sword: Four functions of humor in communication. Communication Theory, 10(3), 310-331. doi:10.1111/j.14682885.2000.tb00194.x

Miller, J. (2013). Monty python's flying circus

Miller, J. S. (2000). Something completely different: British television and american culture (N - Newition ed.). Minneapolis, Minn: University of Minnesota Press. doi:10.5749/j.ctttt9hr 
Mount, H. (2004, ). Alive and well, the great british snob. Daily Telegraph (London, England).

Newcomb, T. (2013, October 15). Which TV Shows Make the Most Money? TIME. Retrieved from http://entertainment.time.com/2013/10/15/which-tv-shows-makethe-most-money/

Peele, R., \& Kadekar, S. (2007). Dimensional models of personality disorders: Refining the research agenda forDSM-vedited by thomas A. widiger, ph.D., erik simonsen, M.D., paul J. sirovatka, M.S., and darrel A. regier, M.D., M.P.H.; arlington, virginia, american psychiatric publishing, inc., 2007, 315 pages, \$55. Psychiatric Services, 58(7), 1016-1017. doi:10.1176/ps.2007.58.7.1016

Prothro, E. T., and Melikian, L. H. (1955). Studies in stereotypes: V. familiarity and the kernel of truth hypothesis.The Journal of Social Psychology, 41(1), 3-10. doi:10.1080/00224545.1955.9714248

Rai, S., and Kumar, V. V. A. (2012). Five factor model of personality and role stress. Indian Journal of Industrial Relations, 48(2), 341.

Romero, E. J., \& Cruthirds, K. W. (2006). The use of humor in the workplace. IEEE Engineering Management Review,34(3), 18-18. doi:10.1109/EMR.2006.261378

Srivastava, S. (2015). Measuring the Big Five Personality Factors. Retrieved October 31, 2015 from http://psdlab.uoregon.edu/bigfive.html.

Tamkins, M. M. (2007). The relation of personality to organization-based self-esteem: An application of the five-factor model of personality

Tatli, E., \& Ozdemir, U. (2014). The Use of Humor in Award-Winning TV Commercials in Hungary. In Marketing and Consumer Behavior: Concepts, Methodologies, 
Tools, and Applications. Hershey: IGI Global.

Terracciano, A., Abdel-Khalek, A. M., Ádám, N., Adamovová, L., Ahn, C., Ahn, H. Division of Occupational Therapy. (2005). National character does not reflect mean personality trait levels in 49 cultures. Science, 310(5745), 96-100. doi:10.1126/science.1117199

Thomas, J. (2011, December 2). Guest post: 8 British TV show adaptations that failed in the US. Retrieved May 12, 2016, from http://www.anglotopia.net/britishentertainment/brit-tv/guest-post-8-british-tv-show-adaptations-that-failed-in-theus/

Tupes, E. C., and Christal, R. E. (1992). Recurrent Personality Factors Based on Trait Ratings. Journal Of Personality, 60(2), 225-251.

Viera, A. J., \& Garrett, J. M. (2005). Understanding interobserver agreement: The kappa statistic. Family Medicine, 37(5), 360.

Waldherr, A., and Muck, P. M. (2011). Towards an integrative approach to communication styles: The interpersonal circumplex and the five-factor theory of personality as frames of reference. Communications : The European Journal of Communication Research, 36(1), 1-27. doi:10.1515/COMM.2011.001

Young, K. (2001). Becoming intercultural: An integrative theory of communication and cross-cultural adaptation. Thousand Oaks, Cal:Sage.

Zwaan, K., Bruin, J. d., \& ebrary, I. (2012). Adapting idols: Authenticity, identity and performance in a global television format (New ed.). Burlington, Vt;Farnham; Ashgate. 


\section{Appendices}

\section{Appendix A: Codebook}

a. Unit of Analysis: Character sequence or confessional

1. Character sequence: "Any thematically continuous scene between one or more characters" (Looney, 2012, p. 42).

2. Confessional: "Any scene in which the character is addressing the camera alone in a confessional manner" (Looney, 2012, p. 42).

\section{b.Humor Styles}

1. Affiliative humor: The main character(s) tend to joke around with others, say witty things, tell amusing stories, laugh with others, and amuse others. The characters seem to be socially extroverted, cheerful, emotionally stable, and concerned for others.

2. Self-enhancing humor: The main character(s) have a tendency to maintain a humorous outlook on life and use humor in emotion regulation and coping, have a tendency to be humorous even when not around other people. The character(s) seem to have high self-esteem and optimism.

3. Aggressive humor: The main character(s) will use sarcasm, pranking, teasing, criticize or manipulate others, and compulsively use humor without regard for the effect on others. The character(s) may be aggressive or hostile.

4. Self-defeating humor: The main character(s) will use humor in an excessively self-disparaging and ingratiating way. They will allow themselves to be the butt of others' jokes. The character(s) may seem depressed, anxious, hostile, or aggressive. 
Appendix B: Content Analysis Coding Scheme

1. Coding Date:

2. Coder:

3. Version:

1 U.S.

2 U.K.

4. Episode Title:

5. Character Sequence Number:

6. Confessional Sequence Number:

7. Character Exchange/Confessional Description:

Humor Style(s) Employed: (more than one humor style may occur within a single continuous sequence/confessional)

0 No

3 Yes

5 Unsure

8. Affiliative humor

9.Self-enhancing humor

10. Aggressive humor

11. Self-defeating humor 


\section{Appendix C: Training Coding Scheme}

\section{Coding Date:}

2. Coder:

3. Comedian name:

\section{Humor style:}

1 Affiliative

3 Self-enhancing

5 Aggressive

7 Self-defeating 